\title{
From Academic Physics to Industry and Money
}

\author{
José Ezratty and Pierre Averbuch, Paris
}

(Association Bernard Gregory)

During the sixties, France, like many other countries at that time, experienced a tremendous expansion of both Universities and government research laboratories. A few people noticed that any activity growing faster than the population must, one day or the other, slow one's expansion, but they were considered as Cassandras. Academic people were contemptuous of industry and the profit motive; nevertheless, they believed their activity to be useful for mankind, while having no idea of the process that made it so. They also imagined themselves to be above any limitation, forgetting that every exponential gives rise to a divergence, which needs to be renormalised.

But natural laws are stronger than human dreams, and after the crisis of May 1968, the possibilities of finding jobs in prestigious Universities or in the CNRS, immediatly after gaining a Ph.D., began to diminish. As almost no-one had even glanced outside the ivory tower, one can understand why many academics thought the end of the world had come. They became anxious thinking that, if no future could be guaranteed to new Ph.D.s, it would become impossible to find and attract new research students; and without them, who will work in the lab? But obviously, this point of view is too cynical.

Anyhow, at the beginning of the seventies, the Grenoble group of the French Physical Society, on the one hand, and the Direction de la Physique in Saclay, on the other, became concerned about the future of new Ph.D.s and they started a systematic job hunting activity on their behalf. Things, we thought, were very simple; we had only to meet industry managers, mainly scientific directors and show them that new Ph.D.s are very good people they have an interest in hiring. But three kinds of psychological obstacles were met, and, although some may be specific to French tradition and culture, they must be quoted here as they may have some universality, at least some europeanality.

First of all, there exist in France many technological Universities, called "Grandes Ecoles", the main ones being more than two centuries old. They give training in both basic and applied matters and, in the domain of the hard sciences, roughly three students out of four graduate there and not in the classical Universities which specialized in the training of teachers. Over centuries, a science Ph.D. had no value to people not interested in becoming a university professor and companies were reluctant to hire them; managers did not know even the meaning of the title. Furthermore they feared that people having spent some time doing academic research would have lost any feeling for truly practical problems (if they ever had any).

Second, research students were themselves wary, believing industry to be dirty, based on the exploitation of workers and they were frightened by the idea of leaving the alma mater. In practice, this reluctance disappeared fast enough, when jobs in industry were the only ones open to them. Moreover once they began to work there and make money, they discovered also the inherent intellectual interest. Nevertheless it is still a problem to convince astronomy research students that the best possibility for them is to go to the weapons industry; who, outside the astronomers and the military, are able to spend a huge amount of money to detect and analyse very weak signals?

The third problem was to obtain the help of our colleagues to hunt jobs. One can present the problem as such: the University is a company whose product is trained people; it has no commercial branch to sell them; so this work must be done by the professors themselves. But they are unable to transform themselves into merchants; their professionnal status and dignity would suffer too much.

Nevertheless despite these difficulties, which are no more than the boundary conditions of the problem, we had some success and soon the Grenoble and the Saclay people began to work in cooperation, discovering that while they were selling the same product to the same clients they had an interest in going together instead of in competition [1]. The market is varied and broad enough; it is better to share one's forces to explore the whole of it.

The initiators advised their colleagues of their action, using meetings of the Physical Society, and soon the Orsay people joined them. Then Bernard Gregory, who was Délégué Général à la Recherche Scientifique et Technique asked the former initiators to generalise this job hunting system to other scientific specialities, and all over the country. Later, when Pierre Aigrain was State Secretary for Research, a non profit organisation was created, and called Association Bernard Gregory.

Presently it has branches in around fifty Universities or public Research Centres, and is funded by the government and industrial companies, even banks. It publishes, and sends to companies, lists of new Ph.D.s looking for jobs, in which, candidates are characterized by brief pertinent information about their training and their scientific abilities. On the other side, the Association advertises in all the institutions where it has branches and also through the French telematic information system, the many jobs open in companies looking for scientists. And, to mention everything, it has an information activity about training by research, mainly through the publication of its bulletin Formation par la Recherche.

Every year more than 500 new Ph.D. students register at the Association, and leave it when finding a job. This represents $25 \%$ of the total flux of science Ph.D.s all over the country; it is too small a proportion, but the big Universities of Paris have for long been unable to run efficient local branches; (is it the typical illness of the dinosaur?). More than $60 \%$ of the students registered at the Association find jobs in industrial firms, a figure that would be higher but for the number of foreign students, mainly from Maghreb, included in the total.

It is clear that the success in this run for jobs depends critically on the scientific specialisation. Mathematics has a very general appeal as although traditionally the flux of formation of mathematicians was regulated only by the needs of teachers, more recently they are offered jobs in industry, banks, insurance, even in broker offices; this is true all over the world, and our technical civilisation may suffer from the lack of maths. teachers for our children. Physicists also have not many difficulties, and now the chemical industry has survived 
its crisis by selling more refined products, the tendency is good for chemists too. Things are now better even for biologists, although the genetic engineering industry is not yet expecting a huge market and a tremendous cashflow. The only difficulty is in the domain of earth sciences: the prices of oil and minerals are still very low, and the training of geologists will probably have to be modified in order that people could be used in civil engineering.

As the people not registered at Association Bernard Gregory do not seem to stay indefinitely unemployed after their thesis, one may raise the question of the utility of this Association. It has probably served as an example and encouraged people to leave the academic institutions to go out into the big world. It still helps some students to get jobs and some companies to find people; this business is as limited as that of the stock exchange: it does nothing, except help the laymen to get into contact with the market. Another point to be raised is that, because its own activity depends on the science job market, the Association has some rough knowledge of it; this may be used by the administration, when it wants to know what exists before taking a decision.

\section{B I PM Bureau International des Poids et Mesures Editor Metrologia and the publications of BIPM}

The BIPM is looking for an experienced Ph.D. level physicist to edit the journal of scientific metrology 'Metrologia' and the scientific publications of the BIPM. The post will become available in October 1989 owing to the retirement of the present editor Dr. R.P. Hudson. A wide knowledge of physics is required as well as an interest in editing and preparing scientific manuscripts for publication. Since many of the BIPM publications are bilingual in English and French, a good knowledge of French is required in addition to the primary linguistic requirement of English.

The BIPM (see BIPM Profile, J. Phys. E 18 (1985) 368-371) is an international organization situated on the outskirts of Paris and offers good conditions of employment similar to those of other international organizations based in Paris.

Applications should include a curriculum vitae and the names of two referees and should be sent by 15 May to: M. le Directeur, BIPM, Pavillon de Breteuil, F-92312 SEVRES Cedex, France.

Further information on this post may be obtained from Dr. R.P. Hudson at the BIPM, Tel. + 33145077070 .

Even more, one may wonder if it will be useful to generalise, and to amplify this activity all over the old Europe, to help the new one. It will probably be necessary at least to inform potential employers about the variety of training in the different countries. Otherwise, how will people be able to recruit outside their traditional boundaries. That may be the main task for the next few years, and could be the subject of another article here, in ten years, ... or more.

\section{REFERENCE}

[1] Europhysics News, 6 (1975) 6, 1.

\section{High $T_{c}$ at Villa Gualino}

\section{Baeriswyl and R. Monnier, Zurich}

Thanks to the efforts of Tullio Regge and Mario Rasetti a new member has recently been added to the family of famous science meeting places in Italy. After Erice, Varenna and Trieste the Institute for Scientific Interchange (ISI), located on a hill overlooking the city of Torino, discretely started its activities some four years ago. With the support of the authorities of the region of Piemonte and of the local industry, a large number of meetings on various topics in physics, biology and social sciences have been held at Villa Gualino, the dreamhouse of a finance magnate of the twenties.

From the outset it was clear to the initiators that the building with over thirty guest-rooms and sizeable office space should be more than just a place of brief encounters. Advantage should be taken of the facilities, to bring people together for longer periods during which they would not only exchange ideas but actively collaborate on a given problem. A first step in the direction of such an "Advanced Study Institute" was taken last fall with a three months long pro- gramme on "High-Temperature Superconductivity: Concepts, Models and Methods", coordinated by D. Baeriswyl, D.K. Campbell, S. Lovesey and R. Zeyher. It was attended by over eighty theoretical physicists from fifteen countries, with an average stay per participant of the order of three weeks.

Each of the visitors had his own desk, but little time was devoted to lonely studies. Intensive discussions turned around the various proposed mechanisms like phonon-mediated strong-coupling superconductivity, Bose-Einstein condensation of local pairs, pairing involving excitons or charge fluctuations or more exotic proposals like the binding of holes immersed in a strongly fluctuating spin liquid. Usually, a debate would be initiated during the seminar talk of a participant or of an experimentalist joining the group for a couple of days to confront the theoreticians with the real world.

It is impossible to measure precisely the outcome of this exciting time at Villa Gualino, as several new research colla- borations were started which will produce visible results only in the future. Many important questions were sharpened and several misunderstandings were eliminated. In addition, the setting was ideal for learning and practising new methods and algorithms. One highlight was the Quantum Monte Carlo method for which important advances have been recently reported, in particular by the Trieste group. These developments were intensively discussed during a short workshop on "Interacting Electrons in Reduced Dimensions" at the beginning of October which generated much interest.

Clearly, such a programme represents an enormous financial commitment with no immediate return. The willingness of the governments of the city of Torino and of the region of Piemonte to support this effort on a long term basis (the programme is due to continue for another three to four months in 1989) demonstrates an usual far-sightedness and trust, trust in ISI and the goals the founders have set for it. 